$621 \cdot 9.015$

\title{
Study on the Generating Process of Machined Surface*
}

\author{
By Keiji Okushima** and Yoshiaki Kakino***
}

\begin{abstract}
Metal cutting process was investigated from the view point of generation of new surface and hence in association with machined surface characteristics.

Discussions were made on the ploughing force on the extreme cutting edge, the depth of the distorted surface layer and the work absorbed in its generation in order to reveal the relation between generating process of ploughing force and surface layer.

Following conclusions are drawn from the present study.

1. A part of the ploughing force consists of the force exerted in generation of distorted surface layer.

2. The work done by cutting edge is from 4 to 7 per cent of the work of all cutting operation under normal cutting conditions.

3. The depth of distorted surface layer in actual cutting is nearly equal to that of theoretical plastic zone which is calculated on the assumption that the ploughing force acts as a concentrated force on the semi-infinite surface of work-piece.
\end{abstract}

\section{Introduction}

There are many methods for manufacturing machine parts from raw materials. In any method, however, the materials are, more or less, deformed and changed in their properties. Especially at the newly created surface and in the layer right below, the mechanical, physical and chemical properties of materials are extremely changed.

The change of such properties generally deteriorates the dimensional accuracy and the material quality, while in some limited cases, such changes can be utilized to obtain more favorable qualities.

The purpose of this study is to investigate metal cutting process from the view point of the generation of the new surface with respect to various characteristics of the machined surface.

During metal cutting, the machining process and the characteristics of machined surface are affected by many factors which are classified as follows.

As the primary factors controlling the cutting process, can be mentioned the mechanical, physical and chemical properties of the work and the tool, the cutting conditions (depth of cut, cutting speed, etc.), the tool geometry (the rake angle, the relief, angle, the nose radius and the tool sharpness radius),

* Received 15th August, 1967.

** Professor, Faculty of Engineering, Kyoto University.

*** Graduate Student, Faculty of Engineering, Kyoto University, Sakyo-ku, Kyoto. the environment surrounding the cutting point, and the rigidity of the mechanical setup employed. The distributions of the stress and temperature in the cutting field are determined by combinations of those factors, according to which the deformation, destruction and thermal transformation of the material may occur in the surface layer and will produce a built up edge, cracks, and burr as well as the final texture of the machined surface consisting of the distorted surface layer, the residual stress and the surface roughness. It is easily supposed that those final characteristics are affected mainly by the phenomena which occur in the workpiecs around the cutting edge.

The first portion of this study makes a theoretical analysis of the ploughing force which is exerted by the extreme cutting edge, the depth of the distorted surface layer and the work absorbed for its generation. Then the interdependence among those terms is discussed based on the experimental data obtained from the cutting test.

\section{Methods for measuring the ploughing force, the depth of the distorted sur- face layer and the work absorbed for its generation}

The edge of the cutting tool generally has a certain roundness, because it is impossible to manufacture a perfectly sharp tool edge. Even if a perfectly sharp edge were obtained, it would become 
blunt as soon as the cutting operation starts and the radius of the cutting edge would increase as the cutting continues.

Therefore the cutting force $R$ which acts on the tool is supposed to consist of the force $Q$ generated on the rake face and the force $P$ generated on the round edge. The latter force $P$ consists, in more detail, of its components acting on every minute element of the edge arc and the wear land of the tool flank.

Masuko proved the existence of this kind of force and termed it as the indentation force ${ }^{(1)}$. Albrecht named the similar force the ploughing force and presented a method to measure it by a graphic procedure based on the cutting force data ${ }^{(2)}$.

Although Albrecht restricted the definition of the ploughing force to the force acting only on the arc of cutting edge, it is easily estimated that the forces on the wear land of the tool flank and a part of the forse on the tool rake just above the cutting edge have some effect on the surface layer, and by the Albrecht's method, the force $P$ is obtained as the resultant of them. Therefore, in this study, the ploughing force is defined as the force around the round cutting edge which supplies the work needed for the generation of the new surface.

The distorted surface layer is generated mainly by the plastic deformation of the work metal during the process of chip formation, and it is affected additionally in the succeeding sequence by the friction working between the moving tool flank and the newly generated surface.
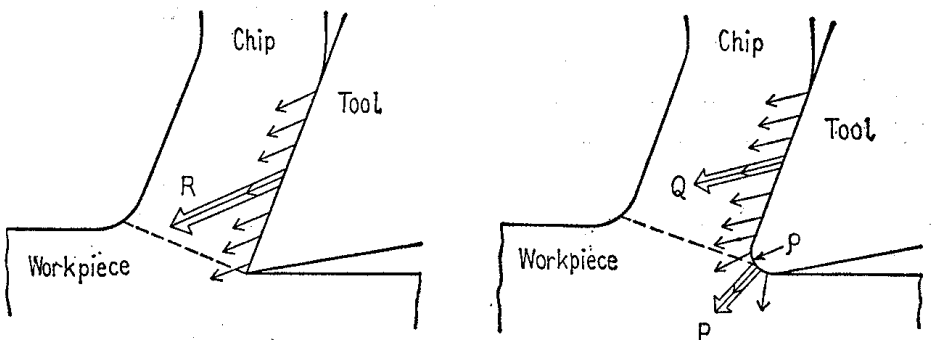

Fig. 1 Sharp tool edge and round tool edge

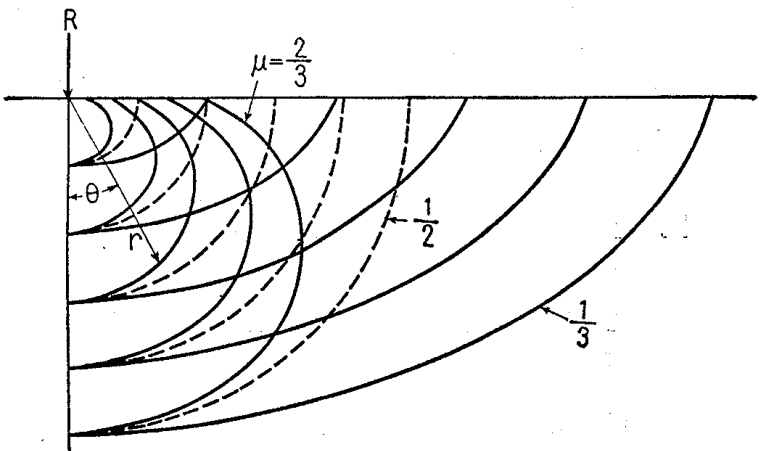

Fig. 2 Contour lines of constant stress level in the work material for the case when the load is applied vertically on the surface of semi-infinite body as a concentrated force
Assuming that those two processes are approximated by an equivalent ploughing force and that the distorted surface layer is the work metal deformed plastically by this ploughing force acting on the work surface, it is possible to estimate the depth of that layer.

For the sake of simplicity, the stress distributions in a semi-infinite body are simulated assuming that the ploughing force acts on the surface as a concentrated force. Using the exponential workhardening relation $\sigma=K \varepsilon^{\mu}$ of the work metal the stress components in the case are given by Sokolov. skii ${ }^{(3)}$ as :

$$
\sigma_{r}=\kappa \cdot 2 \alpha R \frac{\xi(\theta)}{r}, \quad \sigma_{\theta}=\tau_{r \theta}=0, \quad \kappa= \pm 1 \cdots(1)
$$

where

$\sigma_{r}:$ radial stress

$\sigma_{\theta}:$ tangential stress

$\tau_{r \theta}:$ shearing stress

$R$ : concentrated force

$\theta:$ angle shown in Fig. 2

$\xi(\theta)$ : functirn defined as follows

$$
\begin{aligned}
& \xi(\theta)=\left[\frac{\cos (m \theta+\delta)^{\prime}}{\cos \delta}\right]^{\mu} \text {, where } m^{2}=\frac{2 \mu-1}{\mu^{2}} . \\
& \text { when } \mu<1 / 2 \\
& \xi(\theta)=(1+\delta \theta)^{1 / 2}, \quad \text { when } \mu=\frac{1}{2} \\
& \text { and } \xi(\theta)=\left[\frac{\cosh (n \theta+\delta)}{\cosh \delta}\right]^{\mu} \text {, where } n^{2}=\frac{1-2 \mu}{\mu^{2}},
\end{aligned}
$$

In the above, $\alpha$ is a constant defined such that it satisfies the equilibrium conditions of the force which are:

horizontal component of $R$,

$$
R_{H}=-\int_{-\frac{\pi}{2}}^{\frac{\pi}{2}} \sigma_{r} r \sin \theta d \theta
$$

vertical component of $R$,

$$
R_{V}=-\int_{-\frac{\pi}{2}}^{\frac{\pi}{2}} \sigma_{r} r \cos \theta d \theta
$$

$\delta$ is a constant angle between the direction of the force and th? surface, and it is calculated by : $\delta=n \cot ^{-1} \frac{R_{H}}{R_{V}}$

Contour lines of constant stress level (lines of $\sigma_{r}=$ const.) in the work material are shown in Fig. 2 for the case when the load is applied vertically. Different sets of the contour lines exist for various values of the work-hardening coefficient $\mu$ of the material.

Since it holds that $\sigma_{\theta}=\tau_{r \theta}=0$ for the case, the material is deformed plastically in the region where $\sigma_{r} \geqq \sigma_{0}$ (yield stress of the material). Then the depth of distorted sur. 
face layer is given as the maximum depth of this region calculated by Eq. (1) using experimental data on the horizontal component of the ploughing force as $R_{H}$, the vertical component as $R_{V}$, also $\mu$ and $\sigma_{0}$ which are determined by material testing.

In generating a new surface in the metal cutting, the work done by the ploughing force is absorbed to produce the distorted surface layer. Figure 3 shows a typical flow pattern observed on a cross section of the machined surface. The material around the cutting edge is plastically deformed and dragged in the cutting direction, forming the flow pattern, which can be approximately described by an $n$-th order equation $x=l\left(\frac{y}{h}\right)^{n}$ as illustrated in Fig. 3 (b), where $l$ is the dragged distance of surface material, and $h$ is the depth of distorted surface layer.

For every minute elemental depth of $\Delta y$ under the surface, the amount of work needed to produce the plastic deformation in the depth is expressed by:

$$
\Delta W_{P}=\tau_{P} \gamma_{P} \Delta y
$$

where $\tau_{P}$ is the shearing stress of material, and $\gamma_{P}$ is the shearing strain $=\Delta x / \Delta y$

Summing $\Delta W_{P}$ for the whole depth, the work absorbed in generating the distorted surface layer per unit surface area, is given by:

$$
W_{P}=\int_{0}^{h_{1}} \tau_{P} \gamma_{P} d y
$$

If $\tau_{P}$ is constant irrespective of $y$, the above equa-

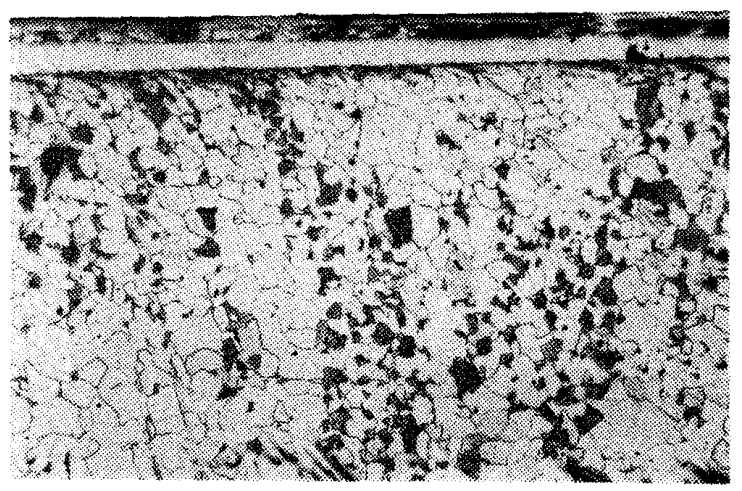

(a)

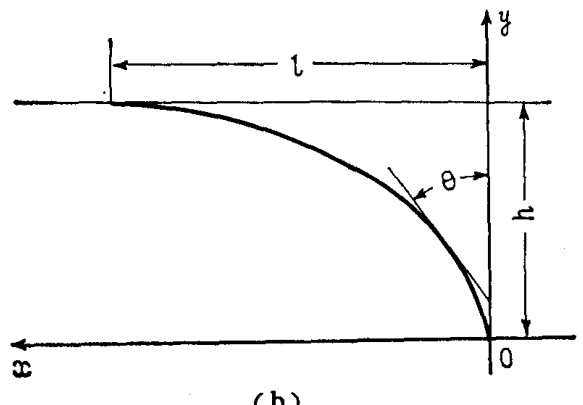

(b)

Fig. 3 Flow pattern of texture observed on a cross section of the machined surface tion is reduced to the same as that given by Thomsen for the calculation of deformation work ${ }^{(4)}$, that is :

$$
W_{P}=\tau_{P} l
$$

This is further transformed into

$$
W_{P}=\tau_{P} h\left(\frac{l}{h}\right)
$$

Since $l / h$ in the above is equal to $\tilde{\gamma}_{P}$, the mean strain in the flow layer, it follows that:

$$
W_{P}=\tau_{P} h \tilde{\gamma}_{P}
$$

By comparing $W_{P}$ as obtained by Eq. (2) based on experimental data of $\tau_{p}$ and $l$, with the total cutting work per unit area of the machined surface $W\left(=F_{h} / b, \quad F_{h}\right.$ : horizontal component of the total cutting force, $b$ : width of cut), the ratio of the surface deformation work to the total cutting work, $W_{P} / W$, is calculated.

The ratio of the horizontal component of the ploughing force $\left(P_{h}\right)$ to that of the total cutting force $\left(F_{h}\right), P_{h} / F_{h}$, can also be obtained from the cutting test: therefore, for the same cutting condition the ratios $W_{P} / W$ and $P_{h} / F_{h}$ could be compared.

However, the secondary plastic flow which arises in the chip is generated by the deformations caused by the tool edge, and also by the friction with the tool rake face. Among those two processes which form the secondary plastic flow, the former is apparently produced by the ploughing force, but those two effects can not be distinguished from each other.

Assuming that the pattern of the secondary flow in the chip produced by the ploughing force is identical to that observed in the work, and therefore the work absorbed by the ploughing force to produce the secondary flow in the chip is equal to that in the workpiece, the ratio of the work by ploughing force to total cutting work is calculated as $2 W_{P} / W$, and this is compared with the force ratio $P_{h} / F_{h}$.

\section{Equipment and procedure for the experiments}

The orthogonal cutting tests and material tests were conducted in order to verify the theory developed in the above. For a high cutting speed of $150 \mathrm{~m} / \mathrm{min}$, the orthogonal cutting tests were conducted using a lathe, and for cutting speeds lower than $45 \mathrm{~m} / \mathrm{min}$, using a shaper.

Machine tool :

(a) Okuma SS 600 Shaper (Maximum stroke $655 \mathrm{~mm}$, power $3.7 \mathrm{~kW}$ )

(b) VDF high speed lathe (Heidenreich and Harbeck; swing $520 \mathrm{~mm}$, maximum center distance $1000 \mathrm{~mm}$, power $15 \mathrm{~kW}$, spindle speed 90 to $5600 \mathrm{rpm}$ ) 
Tool : material,

(a) High speed steel tool SKH-3 (18-4-1 type) for the shaper test,

(b) Cemented carbide tool P10 for the lathe test. geometry. $10 \mathrm{deg}$. rake angle and $8 \mathrm{deg}$. relief angle

Work Material :

(a) $60 \% \mathrm{Cu}-40 \% \mathrm{Zn}$ cold rolled brass plate (thickness $3 \mathrm{~mm}$ )

(b) from the rolled bar of the low carbon steel S 15 C (0.15\% C plain steel), $74 \mathrm{~mm} \mathrm{0.d.}$

(c) from the rolled bar of the medium carbon steel S45 C (0.45\% C plain steel), $94 \mathrm{~mm} \mathrm{0.d.}$ and $3 \mathrm{~mm}$ thick tubes were prepared by machining.

Chemical compositions and hardness of the work materials are listed in Table 1.

Tool sharpness radius: After grinding the cutting edge sharp, the tool sharpness radius was shaped and finished with a honing stone and emery papers. For the inspection of the tool sharpness radius, every tool edge was molded in the plastic resin to replicate the shape. Then the sections of the replica were photographed through a microscope and the sharpness radii were measured.

Cutting speed: $7,11,20,30,45 \mathrm{~m} / \mathrm{min}$ for the shaper test, and $150 \mathrm{~m} / \mathrm{min}$ for the lathe test.

Depth of cut: Various depths up to $0.4 \mathrm{~mm}$ were cut. In order to know the depths of cut precisely in the shaper test, a tool maker's microscope was set on a side of the workpiece, and the distance between machined surface and a reference line was measured before and after cutting, so that the depth of cut might be known by the difference of the successive readings to a $0.01 \mathrm{~mm}$ accuracy.

Cutting force measurement: The main and thrust forces were measured using a three component strain-gauge-type tool dynamometer and recorded by a pen oscillograph recorder.

Measurement of the distorted surface layer:

(a) The thickness of the flow layer: The finished surface is nickel-plated and molded in the plastic resin, then polished and etched to observe the flow pattern by a microscope.

(b) The thickness of the work-hardened layer: Due to the work-hardening in the distorted layer, the hardness at the surface is much higher than in the original metal, and it reduces with the depth from the surface until it reaches the same as that of the original metal at a certain depth as seen in Fig. 4. Therefore the depth of work-hardened layer can be obtained by a microVickers hardness testing.

When measuring the depth of flow layer and that of the work-hardened layer for identical test piece, the latter is always greater than the former. The reason for this is that even a smaller strain can be detected by the difference in the micro-hardness, than by the visual inspection of flow pattern.

In this study, both of these two methods were adopted to measure the depth of the distorted surface layer.

\section{Test results}

4.1 Effect of the tool sharpness radius on the cutting force

In orthogonal cutting of brass at $30 \mathrm{~m} / \mathrm{min}$ cutting speed, the two components of the cutting force

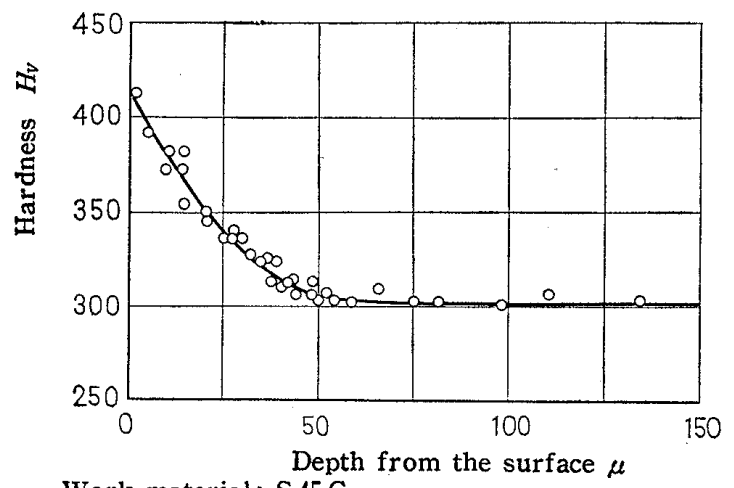

Work material: $\mathrm{S} 45 \mathrm{C}$

Tool material: Cemented carbide P10

Cutting speed: $150 \mathrm{~m} / \mathrm{min}$

Width of cut: $3 \mathrm{~mm}$

Rake angle: $10 \mathrm{deg}$.

Relief angle: 8 deg.

Fig. 4 Distribution of micro-hardness on a cross section of the machined surface

Table 1 Chemical composition and hardness of work material tested

\begin{tabular}{|c|c|c|c|c|c|c|c|c|c|}
\hline \multirow{2}{*}{ Material } & \multicolumn{8}{|c|}{ Chemical composition $\%$} & \multirow{2}{*}{$\begin{array}{l}\text { Hardness } \\
\text { Vickers }\end{array}$} \\
\hline & \multicolumn{2}{|l|}{$\mathrm{Cu}$} & $\mathrm{Pb}$ & \multicolumn{2}{|c|}{$\mathrm{Sn}$} & \multicolumn{2}{|l|}{$\mathrm{Fe}$} & $\mathrm{Zn}$ & \\
\hline Brass & \multicolumn{2}{|c|}{58.25} & 0.174 & \multicolumn{2}{|c|}{0.69} & \multicolumn{2}{|c|}{0.08} & Rest & 112 \\
\hline \multirow{2}{*}{ Material } & \multicolumn{8}{|c|}{ Chemical composition $\%$} & \multirow{2}{*}{$\begin{array}{l}\text { Hardness } \\
\text { Vickers }\end{array}$} \\
\hline & $\mathrm{C}$ & $\mathrm{Si}$ & $\mathrm{Mn}$ & $S$ & $P$ & $\mathrm{Cu}$ & $\mathrm{Ni}$ & $\mathrm{Cr}$ & \\
\hline $\mathrm{S} 15 \mathrm{C}$ & 0.17 & 0.23 & 0.36 & 0.016 & 0.008 & 0.15 & 0.09 & 0.07 & 145 \\
\hline $\mathrm{S} 45 \mathrm{C}$ & 0.47 & 0.27 & 0.68 & 0.021 & 0.019 & 0.09 & 0.06 & 0.12 & 302 \\
\hline
\end{tabular}


were measured at various depths of cut and with tools having various tool sharpness radii. As seen in Fig. 5 ( $a$ ) and ( $b$ ), both of the main and the thrust forces increase with the increased depth of cut. For the increased tool sharpness radius, the thrust force shows far more increase than the main force. (In the figure, $\rho=0$ refers to the sharpest edge obtainable for this study).

From those data Fig. 6 is obtained when connecting points for constant depths of cut and constant tool sharpness radii on a coordinate having the thrust force as the ordinate and the main force as the abscissa. In this diagram, the lines connecting the points of constant depths of cut, are not straight but curved, and in this respect, it is different from Albrecht's results. This means that the direction of the ploughing force $P$ is not constant, and consequently it is impossible to calculate $P$ by the Albrecht's method.

Owing to the above, in this study the ploughing force was assumed not to vary with depth of cut, so that it might be extrapolated from the force data at the zero depth of cut. The ploughing force $P$ was calculated by the above-mentioned procedure for each tool sharpness radius and the results are shown in Fig. 7. It is found in Fig. 7 that when the tool sharpness radius increases, the ploughing force $P$ increases in approximately linear fashion and its direction tends to turn vertical to the finished surface.

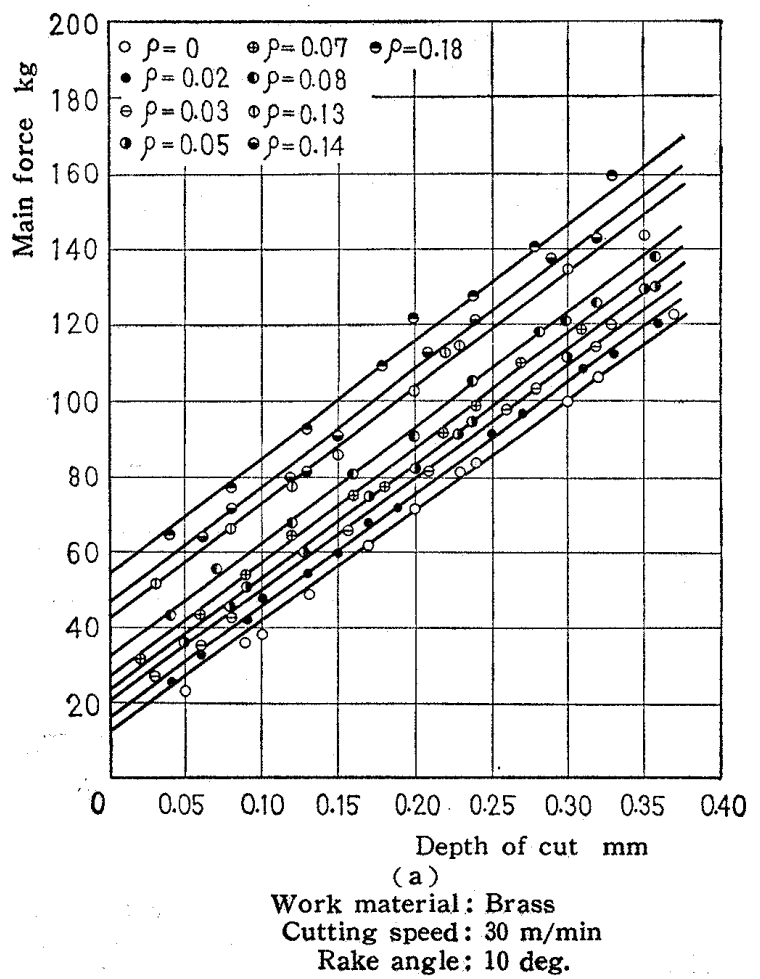

4.2 Effect of the depth of cut on the depth of the distorted surface layer

For various depths of cut in the cutting of brass, the depths of the flow layer were obtained as shown in Fig. 8. The figure shows that the flow layer is deeper when the depth of cut is increased up to $0.2 \mathrm{~mm}$, above which the depth of the flow layer is almost constant. This is closely related to the fact that as far as the depth of cut is under $0.2 \mathrm{~mm}$, and $\rho=0$ in Fig. 5, the plot of cutting force is found below the expected straight line. This means that the work absorbed in generating the surface layer is nearly constnat over $0.2 \mathrm{~mm}$ depth of cut, but it is less for the depth of cut under $0.2 \mathrm{~mm}$.

4.3 Effect of the tool sharpness radius on the depth of the distorted surface layer

For various tool sharpness radii, the test data indicate that the depth of the distorted surface layer increases almost linearly with a larger tool sharpness radius, as shown by Fig. 9. Plotting those depths of flow layer versus the ploughing force data obtained by the identical tool sharpness radii, Fig. 10, it is seen that the depth of flow layer increases linearly with the ploughing force.

4.4 Effect of cutting speed on the cutting force and the ploughing force

The effect of cutting speed on the cutting force in the cutting of brass, Fig. 11, shows that the cutting force increases linearly with the depth of

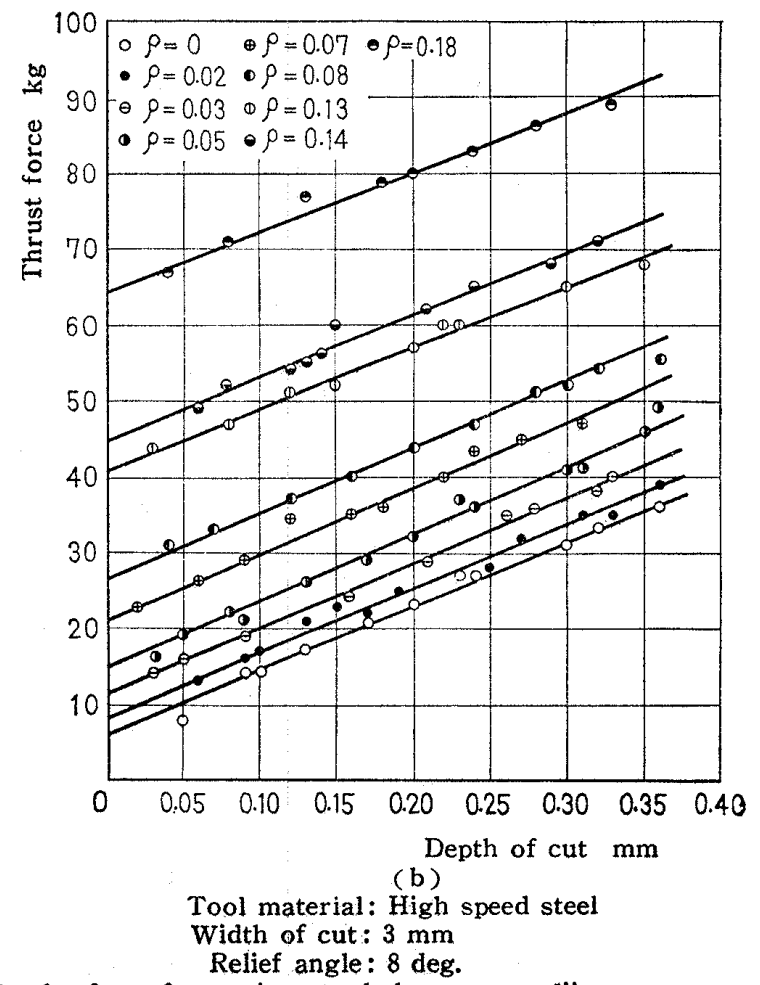

Fig. 5 Relation between cutting force and depth of cut for various tool sharpness radii 
cut, the cutting force tends to fall below the expected straight line under $0.2 \mathrm{~mm}$ depth of cut.

Comparing cutting forces at a constant depth of cut, the cutting force decreases remarkably for higher cutting speeds. Ploughing forces were calculated from the data of Fig. 11, for various cutting speeds, but they were found indifferent to the cutting speed. Only the horizontal component of the ploughing force shows a slight decrease, but the decrement is extremely small.

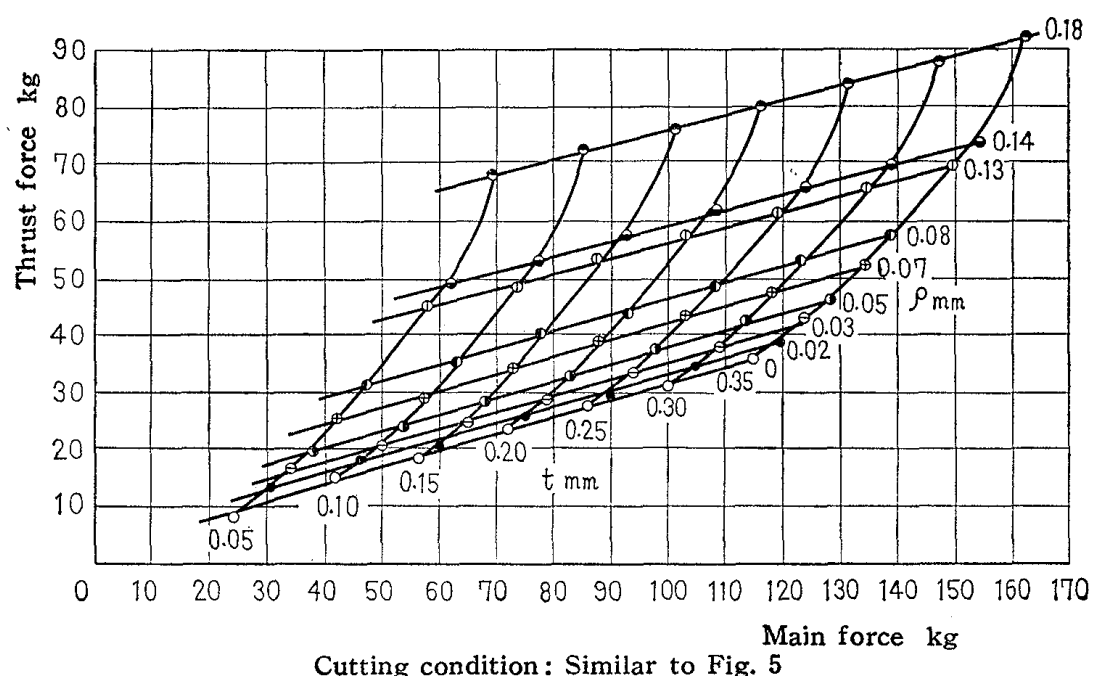

Fig. 6 Relation between main force and thrust force for various depths of cut and various tool sharpness radii

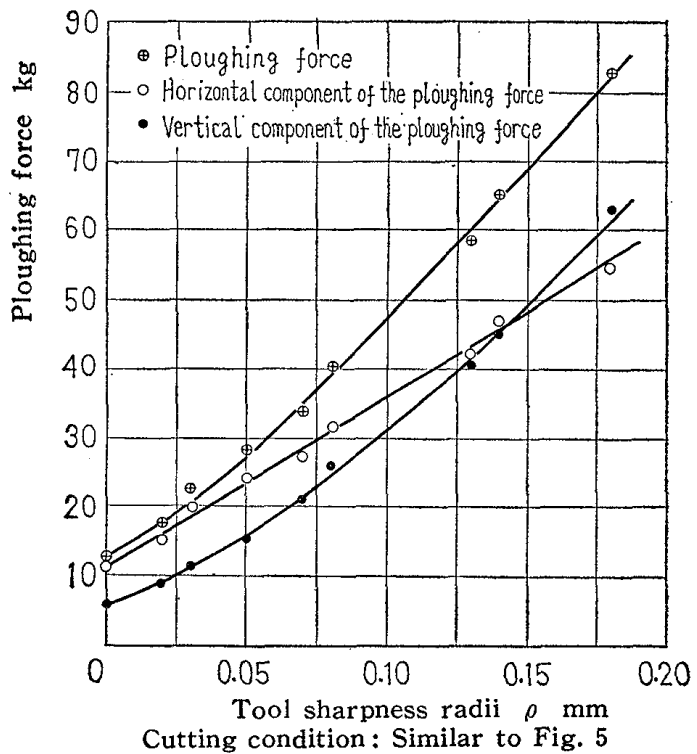

Fig. 7 Relation between the tool sharpness radius and the ploughing force

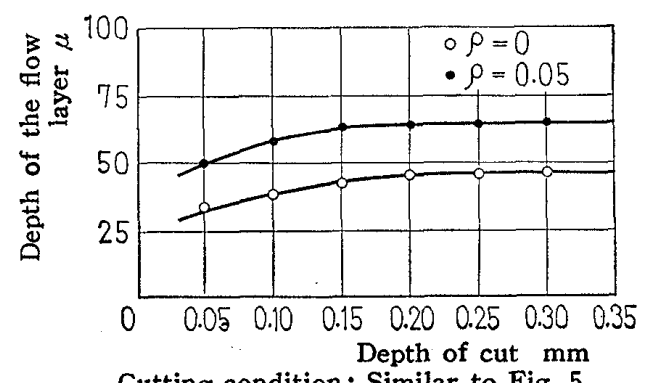

Fig. 8 Relation between the depth of cut and the depth of flow layer
4.5 Effect of the cutting speed on the depth of the distorted surface layer

From the cutting test on the brass work, the effect of cutting speed on the depth of flow layer is found such that a faster cutting speed gives a shallower flow layer, as shown in Fig. 12.

\section{Interpretation of ex- perimental results}

5.1 Comparison of the depth of the distorted surface layers as obtained by the computation and the experiment

It is possible to estimate the depth of the distorted surface layer by theoretical model of the stress distribution expressed by Eq. (1), using the data of the ploughing force as obtained from the cutting test. The yield stress $\sigma_{\theta}$ and the work-hardening coefficient $\mu$ of the work materials should be estimated for the same temperature and strain rate as encountered in the cutting process.

However, since the strain rate and the temperature in deforming zone at metal cutting are not constant but varied, the present study employs approximated values of $\sigma_{0}$ and $\mu$ obtained from a dynamic compression test peformed by Hifomac

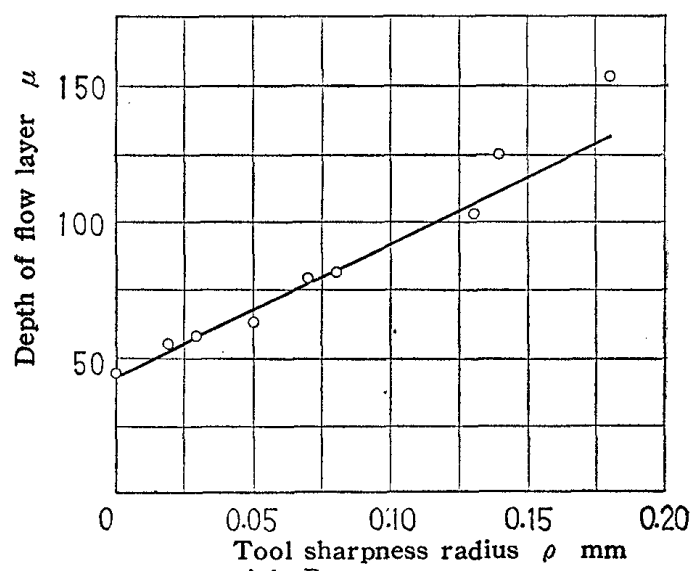

Work material: Brass

Tool material: High speed steel

Cutting speed: $30 \mathrm{~m} / \mathrm{min}$

Width of cut: $3 \mathrm{~mm}$, Depth of cut: $0.2 \mathrm{~mm}$

Rake angle: 10 deg., Relief angle: $8 \mathrm{deg}$.

Fig. 9 Relation between the tool sharpness radius and the depth of flow layer 
press (a high energy rate press powered by triggered exertion of the nitrogen gas energy). Table 3 lists those values used for the theoretical computation. The depths of the plastic zone were calculated by the Eq. (1). As shown in Table 4, the results compare with a fairly good agreement with the depth of the distorted surface layer measured in actual tests.

5.2 The ratio of the work absorbed in generating the distorted surface layer to the total cutting work

Table 5 shows experimental data $\tau, d, l, \tilde{\gamma}$ (those obtained at the test of $0.2 \mathrm{~mm}$ depth of cut), and therefrom calculated ratios $2 W_{P} / W$ and $P_{h} / F_{h}$.

Table 2 Ploughing force obtained by cutting test Breadth of cut : $3 \mathrm{~mm}$, Rake angle: 10 deg., Relief angle: 8 deg.

\begin{tabular}{c|c|c|c|c|c}
\hline Material & $\begin{array}{c}\text { Tool sharp } \\
\text { ness radius } \\
\text { mm }\end{array}$ & $\begin{array}{c}\text { Ploughing } \\
\text { force } \\
P \quad \mathrm{~kg}\end{array}$ & $\begin{array}{c}\text { Horizontal } \\
\text { component } \\
P_{h} \mathrm{~kg}\end{array}$ & $\begin{array}{c}\text { Vertical } \\
\text { compo- } \\
\text { nent } \\
P_{v} \mathrm{~kg}\end{array}$ & $\begin{array}{c}\text { Cutting } \\
\text { speed } \\
\mathrm{W} / \mathrm{min}\end{array}$ \\
\hline \multirow{3}{*}{ Brass } & 0 & 11.7 & 10 & 6 & 30 \\
\cline { 2 - 6 } & 0.02 & 16.6 & 14 & 9 & 30 \\
\hline S 15 C & 0 & 20.5 & 14 & 15 & 150 \\
\hline S 45 C & 0 & 19.8 & 13 & 15 & 150 \\
\hline
\end{tabular}

Table 3 Yield stress and work-hardening coefficient of work material tested

\begin{tabular}{c|c|c|c}
\hline $\begin{array}{l}\text { Work } \\
\text { material }\end{array}$ & $\begin{array}{c}\text { Yield stress } \\
\mathrm{kg} / \mathrm{mm}\end{array}$ & $\begin{array}{c}\text { Work-hardening } \\
\text { coefficient }\end{array}$ & $\begin{array}{l}\text { Method of } \\
\text { material test }\end{array}$ \\
\hline Brass & 41 & 0.160 & tension, static \\
\hline $\mathrm{S} 15 \mathrm{C}$ & 45 & 0.256 & compression, dynamic \\
\hline $\mathrm{S} 45 \mathrm{C}$ & 73 & 0.203 & compression, dynamic \\
\hline
\end{tabular}

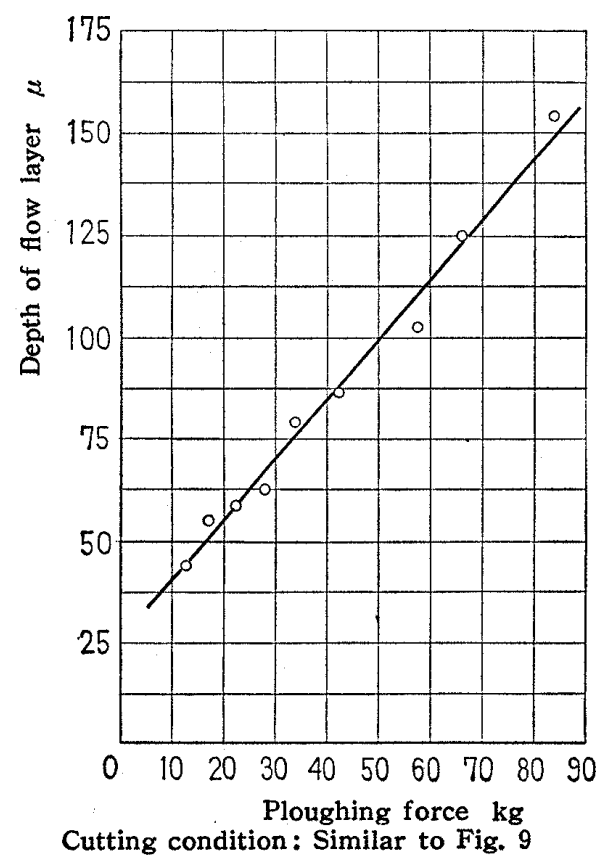

Fig. 10 Relation between the ploughing force and the depth of flow layer
Table 4 Depths of machined layer obtained by cutting test and theoretical calculation

Cutting speed: $30 \mathrm{~m} / \mathrm{min}$ (Brass)

$$
\text { : } 150 \mathrm{~m} / \mathrm{min}(\mathrm{S} 15 \mathrm{C}, \mathrm{S} 45 \mathrm{C} \text { ) }
$$

Depth of cut: $0.2 \mathrm{~mm}$

Breadth of cut: $3 \mathrm{~mm}$

Rake angle: $10 \mathrm{deg}$

Relief angle: $8 \mathrm{deg}$.

\begin{tabular}{l|c|c|c|c}
\hline & & \multicolumn{2}{|c}{ Depth of machined layer } \\
\cline { 3 - 5 } Material & $\begin{array}{c}\text { Tool sharpness } \\
\text { radius } \\
\rho \mathrm{mm}\end{array}$ & $\begin{array}{c}\text { Experimental } \\
\text { Theoretical } \\
\mu\end{array}$ & $\begin{array}{c}\text { Hardened } \\
\text { layer } \\
\mu\end{array}$ & $\begin{array}{c}\text { Flow } \\
\text { layer } \\
\mu\end{array}$ \\
\hline Brass & 0 & 65 & 70 & 44 \\
\hline S 15 C & 0.02 & 97 & 100 & 55 \\
\hline S 45 C & 0 & 119 & 110 & 91. \\
\hline
\end{tabular}

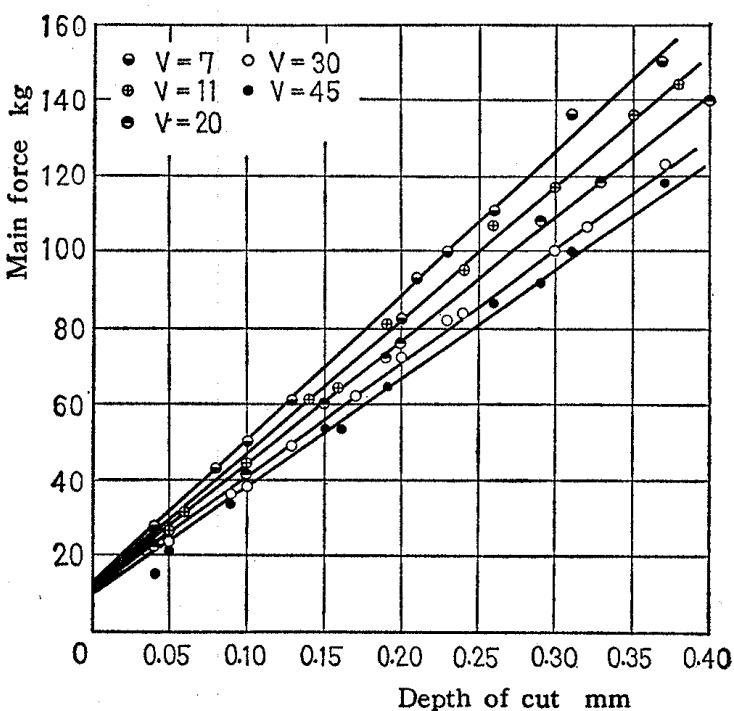

(a)

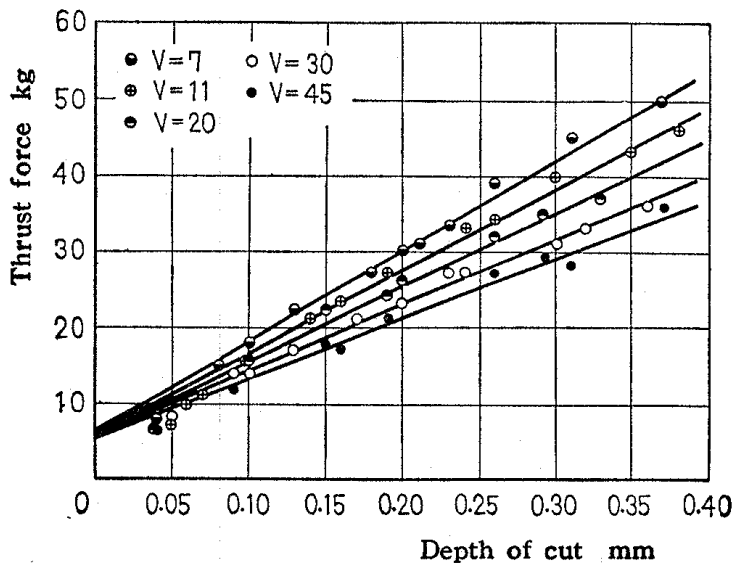

(b)

Work material: Brass Tool material: High speed steel

Tool sharness radius: 0 Width of cut: $3 \mathrm{~mm}$

Rake angle: $10 \mathrm{deg}$. Relief angle: $8 \mathrm{deg}$.

Fig. 11 Relation between the depth of cut and cutting force for various cutting speed $(V)$ 
Table $5 \quad P_{h} / F_{h}$ and $2 W_{p} / W$

Cutting condition: Similar to Table 4

\begin{tabular}{|c|c|c|c|c|c|c|c|c|c|c|c|}
\hline Material & $\begin{array}{c}\tau_{s} \\
\mathrm{~kg} / \mathrm{mm}\end{array}$ & $\begin{array}{c}\rho \\
\mathrm{mm}\end{array}$ & $\begin{array}{l}F_{h} \\
\mathrm{~kg}\end{array}$ & $\begin{array}{l}P_{h} \\
\mathrm{~kg}\end{array}$ & $\frac{P_{h}}{F_{h}} \times 100$ & $\begin{array}{l}d \\
\mu\end{array}$ & $\begin{array}{l}l \\
\mu\end{array}$ & $\tilde{r}$ & $\begin{array}{c}2 W_{P} \\
\mathrm{~kg} / \mathrm{mm}\end{array}$ & $\begin{array}{c}W \\
\mathrm{~kg} / \mathrm{mm}\end{array}$ & $\frac{2 W_{p}}{W} \times 100$ \\
\hline \multirow{7}{*}{ Brass } & \multirow{7}{*}{20.5} & 0 & 72 & 12 & 16.7 & 44 & 27 & 0.6 & 1.1 & 24 & 4.6 \\
\hline & & 0.02 & 76 & 16 & 21.1 & 55 & 33 & 0.6 & 1.4 & 25 & 5.6 \\
\hline & & 0.03 & 79 & 20 & 25.3 & 58 & 38 & 0.7 & 1.6 & 26 & 6.2 \\
\hline & & 0.05 & 83 & 23 & 27.7 & 61 & 55 & 0.9 & 2.3 & 28 & 8.2 \\
\hline & & 0.08 & 93 & 32 & 34.4 & 81 & 77 & 1.0 & 3.2 & 31 & 10.3 \\
\hline & & 0.13 & 103 & 42 & 40.8 & 103 & 158 & 1.6 & 6.5 & 34 & 11.1 \\
\hline & & 0.18 & 115 & 54 & 47.0 & 153 & 270 & 1.8 & 11.1 & 38 & 29.2 \\
\hline$S=15 \mathrm{C}$ & 22.5 & 0 & 79 & 13 & 16.5 & 91 & 94 & 1.0 & 4.2 & 26 & 16.1 \\
\hline $\mathrm{S} 45 \mathrm{C}$ & 36.5 & 0 & 86 & 12 & 14.0 & 42 & 41 & 1.0 & 3.0 & 29 & 10.3 \\
\hline
\end{tabular}

The table shows that the values of $2 W_{P} / W$ are considerably smaller than $P_{h} / F_{h}$. The discrepancy has supposedly arisen due to the error involved in estimating the ploughing force, and also due to the error caused by ignoring other deformation works than the plastic surface work, for instance, the work absorbed in generating the burr and the work-hardening in the distorted surface layer.

\section{Conclusions}

Metal cutting process was investigated from the viewpoint of generation of new surface and the associated characteristics of the machined surface. Theory of the ploughing force, the depth of the distorted] surface layer and the work absorbed in its generation were developed and cutting tests were conducted to supplement the discussions.

The following conclusions are drawn:

1) The amount of the work done by cutting edge ranges from 4 to 7 per cent of the total cutting work of the cutting operation under conventional conditions. This ratio, looking small, is very important for the generation of the new surface.

2) The ploughing force which is exerted by

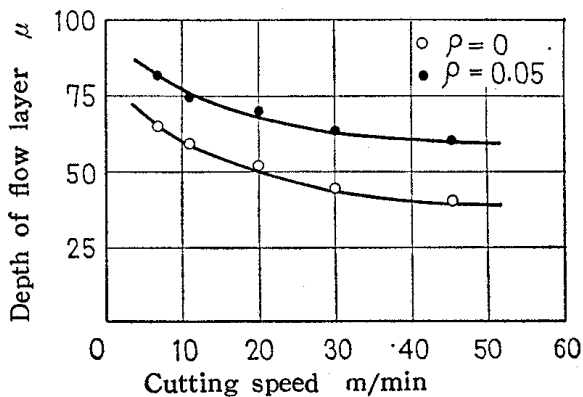

Work material: Brass Tool material: High speed steel Depth of cut: $0.2 \mathrm{~mm}$ Width of cut: $3 \mathrm{~mm}$ Rake angle: $10 \mathrm{deg}$. Relief angle: $8 \mathrm{deg}$.

Fig. 12 Relation between the cutting speed and the depth of flow layer the extreme cutting dege has critical effect on the generation of the new surface, especially in forming the distorted surface layer. The magnitude of the ploughing force found by experiments was almost linear to the tool sharpness radius.

3) A deeper cut produces a deeper distorted surface layer so far as the depth of cut is less than $0.2 \mathrm{~mm}$. Above $0.2 \mathrm{~mm}$ depth of cut, however, the depth of the distorted surface layer is independent of the depth of cut. This is due to the fact that the ploughing force increases with the depth of cut up to $0.2 \mathrm{~mm}$, but it is constant irrespective of cut over $0.2 \mathrm{~mm}$.

4) The depth of the distorted surface layer increases almost linearly with tool sharpness radius. This is related to the fact that the ploughing force increases almost linearly with the tool sharpness radius.

5) A higher cutting speed produces a shallower distorted surface layer without being accompanied by a change of the distribution of ploughing force. This occurs because the distribution of the temperature and the strain rate inside the work material change when the cutting speed changes.

6) The depth of the distorted surface layer observed in the actual test specimen is in good agreement with that calculated by the plastic zone theory based on the assumption that the ploughing force acts as a concentrated force on the semi-infinite surface of the work material.

\section{References}

(1) M. Masuko: Trans. Japan Soc. Mech. Engrs., Vol. 19 No. 78 (1953), p. 32 ; Vol. 22, No. 118 (1956), p. 371.

(2) P. Albrecht: Trans. ASME, Ser. B, Vol. 82, No. 4 (1960), p. 348.

(3) B. B Sokolovskii (translated by Ohashi): Theory of Plasticity, (1959), p. 264. Asakura Shobo.

(4) E. G. Thomsen et al.: Trans. ASME, Vol 75, No. 4 (1953), p. 591 . 